\title{
The relative importance of social class and maternal education for breast-feeding initiation
}

Valeria Skafida*

Department of Social Policy, University of Edinburgh, and the Centre for Research on Families and Relationships, 23 Buccleuch Place, Edinburgh EH8 9LN, UK

Submitted 17 July 2008: Accepted 11 December 2008: First published online 26 February 2009

\begin{abstract}
Objective: To examine changes in breast-feeding take-up rates among young children in Scotland and to assess whether maternal education or occupationbased social class is a stronger and better predictor of breast-feeding take-up.

Design: Binary logistic regression models were developed from the first sweep of the Growing Up in Scotland longitudinal survey, for the two cohorts of children. Setting: A national representative survey for Scotland.

Subjects: A baby cohort of 5012 singletons born over a 12-month period between June 2004 and May 2005, and a toddler cohort of 2732 singletons born over a 12-month period between June 2002 and May 2003.

Results: Mothers from more privileged social classes and those with more educational qualifications resulted as more likely to breast-feed. However, maternal education was a better and more robust predictor of breast-feeding take-up compared with social class. There were no significant differences in breast-feeding take-up between the two cohorts and only minor differences between mothers aged 20-29 years and those who stated an intention to bottle-feed prior to birth.

Conclusions: The study suggests that the importance of maternal education in influencing breast-feeding has been somewhat overlooked in research based in more developed countries. The results indicate that, compared with occupationrelated social class, maternal education is a more informative, accurate and useful lens through which to understand and explain patterns of breast-feeding take-up.
\end{abstract}

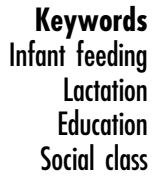

Keywords

Lactation

Social class
Growing policy attention has been paid to the nutrition of infants and the importance of breast milk for child development. Policy documents are based on a wealth of national and international research indicating the positive health outcomes of breast-feeding for mother and child $^{(1-4)}$. At an international level, documents like the WHO Innocenti Declaration ${ }^{(5)}$ and the European Commission's Protection, promotion and support of breastfeeding in Europe ${ }^{(6)}$ reflect the supranational impetus in promoting breast-feeding. At a UK-wide level, this is seen with programmes such as the UK Baby Friendly Initiative. At the Scottish level, the Scottish Joint Breastfeeding Initiative and the Infant Feeding Strategy for Scotland ${ }^{(7)}$ reflect a policy agenda which acknowledges the importance of breast-feeding in improving children's chances for a healthy future. More importantly, Scotland recently introduced the Breastfeeding etc. (Scotland) Act 2005, thus becoming the first nation where breast-feeding has become a legal right ${ }^{(8)}$. This makes Scotland a unique and interesting platform for research on infant feeding.

Despite this policy impetus, a recent Scottish Government research report based on Millennium Cohort Study data showed that breast-feeding take-up in Scotland was low at $64.7 \%$, and notably lower than in England at $72 \cdot 2 \%{ }^{(9)}$. A series of national and international initiatives have endorsed breast-feeding, but it appears that mothers, particularly in Scotland, are less inclined towards the breast-feeding option. While maternal education and social class go some way in explaining differences in breast-feeding trends, there seem to be independent policy-related or socio-cultural elements at work which make mothers in Scotland less likely to breast-feed than their counterparts in England ${ }^{(9)}$.

It is conventional in social research to analyse and explain a variety of social phenomena through social class. A plethora of research has shown that breast-feeding take-up and duration is influenced by the mother's social class, and breast-feeding trends have often been theorised through the lens of occupation-related class categories. Previous studies unanimously suggest that breast-feeding is more common among the more privileged social classes ${ }^{(10-18)}$. Undoubtedly, a relationship between breast-feeding and social class exists and the present paper does not aim to dispute this. However, 
such social class schemes are usually operationalised using information about an individual's employment details, which may or may not be the optimal dimension though which to explore and understand differences in breast-feeding practice.

While a vast body of research has looked at the importance of social class, a smaller number of studies have analysed the relationship between education and breast-feeding. Many of these have focused on developing countries and analogous studies in the developed world are less common. Nevertheless, some evidence indicates that education, which is undoubtedly also correlated with employment outcomes, is a strong predictor of breast-feeding ${ }^{(19-21)}$. The quintennial Infant Feeding Survey report for 2005 showed that $87 \%$ of Scottish mothers who completed their education after the age of 18 years, compared with $68 \%$ who completed it at 17 or 18 years and $48 \%$ at 16 years or less, actually breast-fed at all, with figures having risen for all groups by $2-4 \%$ since $2000^{(22)}$. Recently, a research report by the Scottish Government based on Millennium Cohort Study data found that, in Scotland, mothers with higher educational qualifications had increased chances of breast-feeding their child than those with no qualifications ${ }^{(9)}$. Most strikingly, this report indicated that while social class was a significant predictor of breast-feeding on its own, it fell out of significance when analysed in a model which also included maternal education.

The aim of the present paper is to examine the relative importance of social class and maternal education in predicting breast-feeding incidence. This is not an attempt to disprove that a relationship between social class and breastfeeding exists. More specifically, the paper seeks to explore whether maternal educational qualifications, as a lens for capturing social stratification, are a more insightful, more useful and more robust predictor of breast-feeding take-up than an occupation-based social class scheme may be. This analysis inevitably touches upon the sociological debate regarding the conceptualisation and operationalisation of social class in social research and the associated questions regarding the measurement of social stratification and human capital $^{(23-25)}$. However, while the analysis may contribute to this debate, engaging fully in this discussion is not part of the objectives for the paper.

\section{Methods}

The growing interest in policies for young children and infants has been matched by a growing wealth of social research on babies and young children. However, except for a range of administrative data sources which collect basic information on breast-feeding take-up, few surveys go into the required detail in order to allow for an indepth analysis of the social processes which influence infant feeding. The Infant Feeding Survey for the UK is regularly used for reports on some basic trends of breastfeeding. A richer survey is the UK Millennium Cohort Study (MCS) of young children, which collects data on a series of important demographic variables regarding the mother and enquires about breast-feeding. The Growing Up in Scotland (GUS) longitudinal survey is similar to the MCS in many respects. GUS was launched later than the MCS (2004 and 2001, respectively), thus the GUS sample is younger and the relevant phenomena of interest are more recent. More importantly, GUS is specifically tailored to survey families and children living in Scotland, in the evolving Scottish social and policy context. Thus, GUS was the preferred data source for the analysis.

The GUS survey design is described fully elsewhere ${ }^{(26)}$. Overall, the research methods in the present study are in line with the recommendations for research set out in the European Commission's blueprint for action on breastfeeding ${ }^{(6)}$. In brief, 5217 eligible babies and 2858 toddlers were interviewed for the survey, originally sampled from the Child Benefit Register by the Department of Work and Pensions. Babies born between June 2004 and May 2005 were sampled for the baby cohort, and were approximately 10 months old at the interview. Toddlers born between June 2002 and May 2003 make up the toddler cohort, and were approximately 34 months old at the time of interview.

The sampling frame was stratified by aggregated data zones, which are units created by the Scottish Executive (now the Scottish Government) for reporting 2001 Census small-area statistics. These zones were then sorted by local authority and by the Scottish Index of Multiple Deprivation score. From this hierarchically sorted list, 130 zones were selected at random ${ }^{(27)}$. Separate weights for each sample were applied to account for the stratified sampling procedure, to correct for the different probability of selection for some of the children and to correct for non-response bias.

Interviews were carried out in the homes of the participants using computer-assisted personal interviewing. They mostly contained closed questions and included a self-completion section. The survey aimed to interview the main carer of the sample child, and particularly for the first sweep, which contained questions on breast-feeding, this was to be predominantly (99\% of cases) the mother. Cases where the biological mother was not interviewed and where the child was born in a multiple birth are excluded from the present analysis.

Among a range of topics covered, mothers were asked whether or not they had ever breast-fed the sample child (even if only one time). Additional demographic variables on employment and education were also collected. Mothers were categorised into social class categories according to the National Statistics Socio-Economic Classification (NS-SEC) scheme. This is calculated on the basis of information regarding the individual's working conditions, job security, timing of payments, opportunities for 
promotion and incremental pay ${ }^{(28)}$. Class level for government-funded surveys was previously assigned to the household depending on the status of the highest earner, usually the man, but the NS-SEC scheme classifies the mother and father separately, so a measure for the mother alone was used for the present analysis. The NS-SEC can be arranged in eight, five and three bands. The five-band classification is used in the analysis, as a more detailed classification scheme in combination with other categorical variables severely hampered the analysis. The bands range as follows: (i) managerial and professional; (ii) intermediate; (iii) small employers and own account workers; (iv) lower supervisory and technical; and (v) semi-routine and routine occupations. It should be noted that the long-term unemployed and mothers who never worked are categorised together with those in the routine occupations.

A banded variable indicating the mother's highest educational qualifications was used for the analysis to represent the mother's educational level. Also, a question on whether mothers had received any help or advice about breastfeeding at the time of birth was relevant in the analysis. Mothers were also asked to recall their feeding intentions prior to birth, and whether they intended to breast- or bottle-feed, or if they had no preferences at all. It should be noted, however, that particularly the variable on feeding intentions is subject to recall bias or to re-interpretation 10 or 34 months into the child's life.

Most of the studies reviewed found that birth order (parity) and the age of the mother at the time of birth were also related to breast-feeding ${ }^{(22,29-31)}$, so these two variables were controlled for in the analysis. The mother's age was entered as a continuous variable in the logistic regression analysis, but it is presented in banded form in the descriptive tables. The reviewed literature indicated that other variables, such as the sex of the baby, marital status and employment history, can influence breastfeeding patterns. However, these additional variables, while significant on their own, fell out of significance while testing a full model. All singleton births were analysed where the biological mother of the child was interviewed (toddler cohort $n 2732$, baby cohort $n$ 5012).

Binary logistic regression models were specified for the two cohorts and all analyses were performed using the SPSS statistical software package version $14 \cdot 0$ (SPSS Inc., Chicago, IL, USA). The regression model was arranged with breast-feeding incidence as the dependent variable, and controlled in the first stage for the effects of social class, parity, age of the mother at birth, receipt of breastfeeding advice and anticipated feeding plans. At the second step the model was adjusted for the effects of maternal education. The odds ratios, with confidence intervals and respective significance levels, which were obtained through logistic regression analysis, are reported; these indicate the relative importance of each variable in predicting breast-feeding take-up.

\section{Results and discussion}

Table 1 provides descriptive statistics of the two unweighted samples, featuring the proportions of mothers who match the selected social demographic characteristics explored in the analysis. Among other things it indicates that mothers in the managerial social class category make up $36 \%$ of the total sample, while the real proportion in the population is considerably lower. The weights constructed for the data and applied for the analysis correct for these response bias effects.

\section{Comparing the two cohorts}

Table 2 is based on weighted samples and indicates the proportions of mothers who initiated breast-feeding by selected demographic characteristics, highlighting where there were statistically significant differences in breastfeeding proportions between the two cohorts. Overall, the reported breast-feeding take-up rate was marginally higher, by $1 \%$, among mothers of the baby cohort, but the difference was non-significant $(P=0 \cdot 388)$. The patterns among both cohorts were largely similar.

Breast-feeding take-up was more common among older mothers, and the take-up rate was a statistically significant $4 \%$ higher among mothers of the baby cohort compared with those of the toddler cohort for mothers aged 20-29 years. As previously shown by other research, mothers with degrees or equivalent educational qualifications had the highest breast-feeding rates among both cohorts, as did those in managerial or professional occupations. Unsurprisingly, mothers who stated having received breast-feeding advice had higher breast-feeding take-up rates. The breast-feeding rate among mothers who planned to bottle-feed was slightly lower for the mothers of the baby cohort, which was a substantively unimportant difference, albeit statistically significant.

\section{Comparing social class and education}

Table 3 shows the change in odds ratios and significance levels for the social class variable after controlling for maternal education. What becomes evident is that, for both cohorts, the NS-SEC classification scheme is an adequate predictor of differences in the likelihood of breast-feeding take-up when controlling for other relevant variables. However, when also controlling for maternal education, the significance levels for the social class categories are affected so as to render most of the categories of the variable itself non-significant for both cohorts, but especially for the baby cohort.

The first step of the model indicates that social class is a strong predictor of breast-feeding take-up for the mothers of both cohorts. For both cohorts, the small employer and own account worker category features as not being significantly different in terms of breast-feeding odds from the reference category, the managerial and professional group. Perhaps this indicates that the two categories of 
Table 1 Characteristics of unweighted baby and toddler samples

\begin{tabular}{|c|c|c|c|c|}
\hline & \multicolumn{2}{|c|}{ Baby cohortt } & \multicolumn{2}{|c|}{ Toddler cohortt } \\
\hline & $n$ & $\%$ & $n$ & $\%$ \\
\hline \multicolumn{5}{|l|}{ If child was ever breast-fed } \\
\hline Yes & 3119 & $61 \cdot 7$ & 1673 & $60 \cdot 9$ \\
\hline No & 1935 & $38 \cdot 3$ & 1076 & $39 \cdot 1$ \\
\hline Total & 5054 & $100 \cdot 0$ & 2749 & $100 \cdot 0$ \\
\hline \multicolumn{5}{|l|}{ Parity } \\
\hline First birth & 2473 & $48 \cdot 9$ & 1284 & $46 \cdot 7$ \\
\hline Later birth & 2581 & $51 \cdot 1$ & 1465 & $53 \cdot 3$ \\
\hline Total & 5054 & $100 \cdot 0$ & 2749 & $100 \cdot 0$ \\
\hline \multicolumn{5}{|l|}{ Age of mother at birth of sample child } \\
\hline Under 20 years & 348 & $6 \cdot 9$ & 179 & $6 \cdot 5$ \\
\hline $20-29$ years & 2053 & $40 \cdot 6$ & 1113 & $40 \cdot 5$ \\
\hline $30-40$ years & 2481 & $49 \cdot 1$ & 1380 & $50 \cdot 2$ \\
\hline 40 years or older & 171 & $3 \cdot 4$ & 76 & $2 \cdot 8$ \\
\hline Valid total & 5053 & $100 \cdot 0$ & 2748 & $100 \cdot 0$ \\
\hline Missing & 1 & 0.0 & 1 & 0.0 \\
\hline Total & 5054 & $100 \cdot 0$ & 2749 & $100 \cdot 0$ \\
\hline \multicolumn{5}{|l|}{ Mother's social class } \\
\hline Managerial and professional & 1817 & $36 \cdot 0$ & 1006 & $36 \cdot 6$ \\
\hline Intermediate & 983 & $19 \cdot 4$ & 444 & $16 \cdot 2$ \\
\hline Small employers and own account workers & 196 & 3.9 & 131 & $4 \cdot 8$ \\
\hline Lower supervisory and technical & 305 & $6 \cdot 0$ & 170 & $6 \cdot 2$ \\
\hline Semi-routine and routine & 1504 & $29 \cdot 8$ & 855 & $31 \cdot 1$ \\
\hline Valid total & 4805 & $95 \cdot 1$ & 2606 & $94 \cdot 8$ \\
\hline Missing & 249 & 4.9 & 143 & $5 \cdot 2$ \\
\hline Total & 5054 & $100 \cdot 0$ & 2749 & $100 \cdot 0$ \\
\hline \multicolumn{5}{|l|}{ Mother's education } \\
\hline Degree or equivalent & 1404 & $27 \cdot 8$ & 761 & $27 \cdot 7$ \\
\hline Vocational qualification below degree & 1861 & $37 \cdot 0$ & 1019 & $37 \cdot 1$ \\
\hline Higher grade or equivalent & 410 & $8 \cdot 1$ & 204 & $7 \cdot 4$ \\
\hline Standard grade or equivalent & 904 & $17 \cdot 9$ & 485 & $17 \cdot 6$ \\
\hline No qualifications & 450 & 8.9 & 268 & $9 \cdot 7$ \\
\hline Valid total & 5039 & $99 \cdot 7$ & 2737 & $99 \cdot 6$ \\
\hline Missing & 12 & $0 \cdot 1$ & 10 & $0 \cdot 4$ \\
\hline Other & 3 & $0 \cdot 2$ & 2 & $0 \cdot 1$ \\
\hline Total & 5054 & $100 \cdot 0$ & 2749 & $100 \cdot 0$ \\
\hline \multicolumn{5}{|l|}{ Feeding method planned prior to birth } \\
\hline Breast-feeding & 3289 & $65 \cdot 1$ & 1729 & $62 \cdot 9$ \\
\hline Bottle-feeding & 1451 & $28 \cdot 7$ & 828 & $30 \cdot 1$ \\
\hline No strong preference & 305 & $6 \cdot 0$ & 190 & $6 \cdot 9$ \\
\hline Valid total & 5045 & $99 \cdot 8$ & 2747 & $99 \cdot 9$ \\
\hline Missing & 9 & 0.2 & 2 & $0 \cdot 1$ \\
\hline Don’t know & 7 & $0 \cdot 1$ & 2 & $0 \cdot 1$ \\
\hline Refusal & 2 & $0 \cdot 0$ & 0 & 0.0 \\
\hline Total & 5054 & $100 \cdot 0$ & 2749 & $100 \cdot 0$ \\
\hline \multicolumn{5}{|l|}{ If mother received breast-feeding help or advice } \\
\hline Yes & 3765 & $74 \cdot 5$ & 2033 & $74 \cdot 0$ \\
\hline No & 1284 & $25 \cdot 4$ & 713 & $25 \cdot 9$ \\
\hline Valid total & 5049 & 99.9 & 2746 & 99.9 \\
\hline Missing & 5 & 0.0 & 3 & 0.1 \\
\hline Don't know & 3 & 0.1 & 3 & 0.1 \\
\hline Refusal & 2 & 0.1 & 0 & 0.0 \\
\hline Total & 5054 & $100 \cdot 0$ & 2749 & $100 \cdot 0$ \\
\hline
\end{tabular}

tBoth samples are filtered for single births and biological mothers only.

mothers are fairly similar in terms of other characteristics which in turn influence breast-feeding outcomes.

The small employers and own account workers as a category is largely made up of self-employed mothers, with $98 \%$ and $97 \%$ for the baby and toddler cohort, respectively, reporting to be self-employed. The social make-up of the self-employed is a growing field of interest. Some research has suggested that, given the heterogeneity of this group, it would be more useful to subdivide the self-employed according to skills and educational qualifications for a more insightful analysis, particularly as many of today's self-employed are at the higher end of the income and education scale ${ }^{(32,33)}$.

A brief analysis of the sample showed a significant difference between the income distribution of employees and self-employed mothers for both the baby and the toddler cohorts $(P \leq 0 \cdot 001$ and $P \leq 0 \cdot 05$, respectively), and a marginally significant difference in educational qualifications between the two groups among the mothers of toddlers only $(P \leq 0 \cdot 05)$. Among self-employed mothers in the 
Table 2 Breast-feeding incidence by sociodemographic characteristics: differences between cohorts (weighted samples)

\begin{tabular}{|c|c|c|c|c|}
\hline \multirow[b]{2}{*}{ Mothers who breast-fed their child } & \multicolumn{2}{|c|}{ Baby cohortt } & \multicolumn{2}{|c|}{ Toddler cohortt } \\
\hline & $n$ & $\%$ & $n$ & $\%$ \\
\hline \multicolumn{5}{|l|}{ Sex of sample child } \\
\hline Male & 1563 & $60 \cdot 5$ & 815 & $58 \cdot 0$ \\
\hline Female & 1463 & $60 \cdot 2$ & 807 & $60 \cdot 8$ \\
\hline Total (baby $n 5012$, toddler $n 2732$ ) & 3026 & $60 \cdot 4$ & 1622 & $59 \cdot 4$ \\
\hline \multicolumn{5}{|l|}{ Parity } \\
\hline First birth & 1574 & $62 \cdot 8$ & 818 & $61 \cdot 7$ \\
\hline Later birth & 1452 & $58 \cdot 0$ & 804 & $57 \cdot 1$ \\
\hline Total (baby $n 5012$, toddler $n 2732$ ) & 3026 & $60 \cdot 4$ & 1622 & $59 \cdot 4$ \\
\hline \multicolumn{5}{|l|}{ Age of mother at birth of sample child } \\
\hline Under 20 & 131 & $32 \cdot 7$ & 73 & $34 \cdot 8$ \\
\hline $20-29$ years $^{*}$ & 1158 & $54 \cdot 3$ & 588 & $50 \cdot 4$ \\
\hline $30-40$ & 1622 & $69 \cdot 9$ & 915 & $70 \cdot 9$ \\
\hline 40 years or older & 114 & $73 \cdot 5$ & 46 & $70 \cdot 8$ \\
\hline Total (baby $n 5012$, toddler $n$ 2731) & 3025 & $60 \cdot 4$ & 1622 & $59 \cdot 4$ \\
\hline \multicolumn{5}{|l|}{ Mother's social class } \\
\hline Managerial and professional & 1360 & $78 \cdot 9$ & 755 & $78 \cdot 8$ \\
\hline Intermediate & 586 & $60 \cdot 4$ & 268 & $60 \cdot 5$ \\
\hline Small employers and own account workers & 135 & $72 \cdot 6$ & 84 & $67 \cdot 7$ \\
\hline Lower supervisory and technical & 148 & $48 \cdot 2$ & 82 & $47 \cdot 7$ \\
\hline Semi-routine and routine & 710 & $45 \cdot \overline{8}$ & 375 & $42 \cdot 6$ \\
\hline Total (baby $n 4737$, toddler $n 2578$ ) & 2939 & $62 \cdot 0$ & 1564 & $60 \cdot 7$ \\
\hline \multicolumn{5}{|l|}{ Mother's education } \\
\hline Degree or equivalent & 1150 & $86 \cdot 8$ & 603 & $84 \cdot 0$ \\
\hline Vocational qualification below degree & 1084 & $58 \cdot 5$ & 599 & $58 \cdot 6$ \\
\hline Higher grade or equivalent & 265 & $64 \cdot 5$ & 129 & 63.5 \\
\hline Standard grade or equivalent & 381 & $40 \cdot 7$ & 194 & $39 \cdot 1$ \\
\hline No qualifications & 140 & $29 \cdot 6$ & 94 & $33 \cdot 5$ \\
\hline Total (baby $n 4997$, toddler $n 2721$ ) & 3020 & $60 \cdot 4$ & 1619 & $59 \cdot 5$ \\
\hline \multicolumn{5}{|l|}{ Feeding method planned prior to birth } \\
\hline Breast-feeding & 2814 & $87 \cdot 7$ & 1487 & $88 \cdot 1$ \\
\hline Bottle-feeding ${ }^{\star}$ & 58 & $3 \cdot 9$ & 51 & $6 \cdot 0$ \\
\hline No strong preference & 151 & $49 \cdot 5$ & 83 & $43 \cdot 7$ \\
\hline Total (baby $n 5001$, toddler $n 2730$ ) & 3023 & $60 \cdot 4$ & 1621 & $59 \cdot 4$ \\
\hline \multicolumn{5}{|l|}{ If mother received breast-feeding help or advice } \\
\hline Yes & 2511 & $67 \cdot 6$ & 1324 & $65 \cdot 4$ \\
\hline No & 514 & $39 \cdot 9$ & 298 & $42 \cdot 2$ \\
\hline Total (baby $n 5005$, toddler $n 2729$ ) & 3025 & $60 \cdot 4$ & 1622 & $59 \cdot 4$ \\
\hline
\end{tabular}

*Significant at $P \leq 0.05$.

tBoth samples are filtered for single births and biological mothers only.

baby cohort, $32 \%$ were in the top income quartile compared with $22 \%$ of mothers who were employees, with the respective figures being $35 \%$ and $25 \%$ for the toddler cohort. As for education, $40 \%$ of self-employed mothers compared with $34 \%$ of those working as employees had a degree or equivalent for the baby cohort, with the respective figures being 36\% and 33\% for the toddler cohort.

After controlling for the effects of maternal educational qualifications in the model, there was a notable decrease in the predictive power of social class, for both cohorts. Most class categories dropped out of significance for both cohorts, with changes in significance being more marked for the babies, potentially also due to the larger sample size of the baby cohort. More importantly, even with social class in the model, maternal education resulted as being a highly important predictor in the model, for both cohorts. In response to the research question, the above evidence indicates that maternal education is a relatively better and stronger predictor of breast-feeding take-up, and a more useful conceptual tool for understanding breast-feeding trends than is an occupationally based measure of social class. While education and occupational outcomes are correlated, education has a more direct influence on breast-feeding outcomes than does employment-related social class. It may be that having spent an extended time in formal education renders mothers more able to educate themselves on further topics, such as infant nutrition. Perhaps more educated mothers are more likely to be aware of, and search for relevant information regarding optimal infant nutrition, and are more likely to attempt to breast-feed their own infant.

The logistic regression results indicate that there is to some degree a linear positive trend between breastfeeding take-up and education, where mothers with no qualifications result as having an $80 \%$ lower chance for the baby cohort, and a $60 \%$ lower chance for the toddler cohort, of initiating breast-feeding compared with those with degrees or equivalent, who were the most likely to initiate breast-feeding. The mothers with vocational qualifications, however, resulted as being less likely to 
Table 3 Odds ratios for breast-feeding by social class before and after adjusting for maternal education

\begin{tabular}{|c|c|c|c|c|}
\hline & \multicolumn{2}{|c|}{$\begin{array}{l}\text { Model adjusted for social class, receipt of breast- } \\
\text { feeding advice, breast-feeding plans, parity and age }\end{array}$} & \multicolumn{2}{|c|}{$\begin{array}{l}\text { Model also adjusted for maternal } \\
\text { educational qualifications }\end{array}$} \\
\hline & OR & $95 \% \mathrm{Cl}$ & OR & $95 \% \mathrm{Cl}$ \\
\hline \multicolumn{5}{|l|}{ Baby cohortt (n 5012) } \\
\hline \multicolumn{5}{|l|}{ Mother's social class } \\
\hline Managerial and professional & 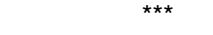 & & * & \\
\hline Intermediate & $0 \cdot 60^{* \star *}$ & $0.46,0.79$ & $0 \cdot 89$ & $0 \cdot 67,1 \cdot 18$ \\
\hline Small employers and own account workers & $1 \cdot 20$ & $0 \cdot 67,2 \cdot 14$ & $1 \cdot 81$ & $0.99,3.30$ \\
\hline Lower supervisory and technical & $0 \cdot 47^{\star \star \star}$ & $0.32,0.69$ & 0.73 & $0.48,1.09$ \\
\hline Semi-routine and routine & $0 \cdot 44^{\star}$ & $0.35,0.57$ & $0 \cdot 78$ & $0 \cdot 59,1 \cdot 03$ \\
\hline \multicolumn{5}{|l|}{ Mother's education } \\
\hline Degree or equivalent & & & 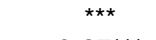 & \\
\hline Vocational qualifications below degree & & & $0 \cdot 37^{\star \star *}$ & $0 \cdot 28,0.50$ \\
\hline Higher grade or equivalent & & & $0 \cdot 44^{\star \star *}$ & $0.30,0.67$ \\
\hline Standard grade or equivalent & & & $0 \cdot 27^{\star \star \star}$ & $0 \cdot 19,0 \cdot 38$ \\
\hline No qualifications & & & $0 \cdot 21^{\star \star \star}$ & $0 \cdot 13,0 \cdot 33$ \\
\hline \multicolumn{5}{|l|}{ Toddler cohortt ( $n$ 2732) } \\
\hline \multicolumn{5}{|l|}{ Mother's social class } \\
\hline Managerial and professional & $\star * * *$ & & & \\
\hline Intermediate & $0.53^{* \star *}$ & $0.36,0.76$ & $0 \cdot 67$ & $0.45,1 \cdot 00$ \\
\hline Small employers and own account workers & 0.67 & $0 \cdot 36,1 \cdot 22$ & $0 \cdot 81$ & $0 \cdot 43,1.51$ \\
\hline Lower supervisory and technical & $0 \cdot 37^{\star \star *}$ & $0.22,0.62$ & $0 \cdot 49^{*}$ & $0 \cdot 28,0 \cdot 83$ \\
\hline Semi-routine and routine & $0 \cdot 43^{\star \star \star}$ & $0.31,0.60$ & $0 \cdot 63^{*}$ & $0.43,0.92$ \\
\hline \multicolumn{5}{|l|}{ Mother's education } \\
\hline Degree or equivalent & & & 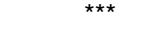 & \\
\hline Vocational qualifications below degree & & & $0 \cdot 61^{*}$ & $0.41,0.89$ \\
\hline Higher grade or equivalent & & & $0 \cdot 74$ & $0 \cdot 42,1 \cdot 31$ \\
\hline Standard grade or equivalent & & & $0 \cdot 38^{\star \star \star}$ & $0.24,0.60$ \\
\hline No qualifications & & & $0 \cdot 41^{\star}$ & $0 \cdot 23,0 \cdot 71$ \\
\hline
\end{tabular}

*Significant at $P \leq 0.05$.

*** Significant at $P \leq 0.001$.

tBoth samples are filtered for single births and biological mothers only.

breast-feed than mothers with higher grades or equivalent, despite having achieved more educational qualifications. A brief analysis of the data indicated that $28 \%$ of mothers with higher grades or equivalent were in managerial occupations compared with $26 \%$ of those with vocational qualifications for the baby cohort (NS, $P=0.065$ ), with the respective figures being $40 \%$ and $25 \%$ for the toddler cohort (significant, $P \leq 0 \cdot 001$ ). So, while social class and educational qualifications generally go hand in hand, mothers who opt for vocational qualifications seem to be associated with a less privileged outcome in terms of occupation and social class than those with higher grades or equivalent, despite having spent more time in education. Perhaps mothers who choose vocational qualifications tend to have other attributes which are correlated with a less favourable social context for breast-feeding compared with mothers with a higher grade or equivalent, but this would require further research.

\section{Conclusion}

In conclusion, previous studies have shown that social class is a strong predictor of breast-feeding take-up, and mothers in more privileged classes are more likely to breast-feed their infants than their less privileged counterparts.
However, while a large body of research has concentrated on the importance of social class, the importance of maternal education has been somewhat overlooked. The present findings suggest that higher educational qualifications are associated with a higher likelihood of breastfeeding take-up. More importantly, though, while social class is a useful predictor of breast-feeding patterns, maternal education is a relatively more useful and robust dimension through which to explain and understand differences in breast-feeding take-up. More educated mothers might be more up to date with the recommendations made by health authorities and spending more time in formal education might render mothers more willing, more likely and more able to pursue practices associated with optimal child development, such as breast-feeding.

It is hoped the findings reported in the present paper may inform future research on infant feeding so that the importance of maternal education is not overlooked in future work. The implications for social policy based on the findings are very general and the evidence merely suggests that an increased investment in formal education could potentially be a way to address, among other issues, low take-up rates for breast-feeding. However, the reasons why education is so important are likely to be complex and educational qualifications could be capturing different unmeasured or immeasurable factors related to a mother's aspirations and beliefs about feeding. 
If this is the case, policy initiatives promoting higher education participation could be found to be inadequate. Furthermore, raising higher education participation rates is unlikely to be a feasible solution, and would require a much larger budget for Scottish universities, set at $£ 263$ million for 2008. Currently, projections for Scotland actually foresee a drop in higher education participation rates over the coming decades ${ }^{(34)}$. More importantly, participation rates in higher education are systematically lower among lower-income and more disadvantaged groups and simply promoting higher education is likely to be unsuccessful and perhaps undesirable ${ }^{(34)}$.

More direct intervention measures could aim at improving current initiatives, potentially making antenatal classes more accessible in more disadvantages areas, making information more easily available to those with limited access to the Internet, or improving support by qualified midwives at the time of birth and during the following days. Such measures would adhere to recent advice by the Scottish National Breastfeeding Adviser (2005) with respect to the European blueprint for action, as they would directly address the particular needs of those groups of mothers who are least likely to breast-feed ${ }^{(35)}$.

\section{Acknowledgements}

This research was made possible by financial support provided by the Economic and Social Research Council (Grant number PTA-033-2006-00017) and the Scottish Centre for Social Research. There is no conflict of interest. I am grateful for the advice provided by Professor Fran Wasoff and Dr Alison Smith and for the support of the Centre for Research on Families and Relationships. I am also grateful to all the families who took the time to participate in the Growing Up in Scotland survey.

\section{References}

1. Fewtrell MS (2004) The long term benefits of having been breastfed. Curr Pediatr 14, 97-103.

2. Howie PW, Forsyth JS, Ogston SA, Clark A \& Florey C (1990) Protective effects of breastfeeding against infection. BMJ 300, 11-16.

3. Sadauskaite-Kuenhne V, Ludvigsson J, Padaiga Z, Jasiskiene E \& Samuelsson U (2004) Longer breastfeeding is an independent protective factor against development of type 1 diabetes mellitus in childhood. Diabetes Metab Res Rev 20, 150-157.

4. Wilson AC, Forsyth JS, Greene SA, Irvine L, Hau C \& Howie PW (1998) Relation of infant diet to childhood health: seven-year follow-up of cohort of children in Dundee infant feeding study. BMJ 316, 21-25.

5. World Health Organization (1990) Innocenti Declaration on the Protection, Promotion and Support of Breastfeeding. Produced and adopted at the WHO/UNICEF Meeting on Breastfeeding in the 990's: A Global Initiative, Spedale degli Innocenti, Florence, Italy, 30 July-1 August 1990; available at http://www.unicef.org/programme/breastfeeding/ innocenti.htm
6. European Commission, EU Project on Promotion of Breastfeeding in Europe (2004) Protection, promotion and support of breastfeeding in Europe: a blueprint for action. Presented at EU Conference on Promotion of Breastfeeding in Europe, Dublin Castle, Ireland, 18 June 2004; available at http://www.iblce-europe.org/Download/ Blueprint/Blueprint\%20English.pdf

7. Scottish Executive (2006) Infant Feeding Strategy for Scotland: A Consultation Paper. Edinburgh: The Scottish Executive.

8. The Scottish Parliament (2005) Breastfeeding etc. (Scotland) Act 2005. 2005 asp 1; available at http://www. scottish.parliament.uk/business/bills/15-breastfeeding/index. htm

9. Dex S (2008) Millennium Cohort Study - Exploration of Some Distinctive Results for Scotland. http://openscotland.gov.uk/Publications/2007/12/18133613/0 (accessed January 2009).

10. Avishai O (2007) Managing the lactating body: the breastfeeding project and privileged motherhood. Qual Sociol 30, 135-152.

11. Earland J, Ibrahim SO \& Harpin VA (1997) Maternal employment: does it influence feeding practices during infancy? J Hum Nutr Diet 10, 305-311.

12. Hamlyn B, Brooker S, Oleinikova K \& Wands S (2002) Infant Feeding 2000: A Survey conducted on behalf of UK Health Departments by BMRB Social Research. London: The Stationery Office.

13. Houston MJ, Howie PW, Smart L, McArdle T \& McNeilly AS (1983) Factors affecting the duration of breast feeding: 2. Early feeding practices and social class. Early Hum Dev $\mathbf{8}$, 55-63.

14. Jeliffe DB \& Jeliffe EFP (1978) Human Milk in the Modern World: Psychosocial, Nutritional and Economic Significance. Oxford: Oxford University Press.

15. Jones A, West R \& Newcombe G (1986) Maternal characteristics associated with the duration of breast-feeding. Midwifery 2, 141-146.

16. Kelly YJ \& Watt RG (2005) Breast-feeding initiation and exclusive duration a 6 months by social class - results from the Millennium Cohort Study. Public Health Nutr 8, $417-421$.

17. Martin J \& White A (1988) Infant Feeding 1985. London: HMSO.

18. Power C \& Matthews S (1997) Origins of health inequalities in a national population sample. Lancet 350, 1584-1589.

19. Ludvigsson JF \& Ludvigsson J (2005) Socio-economic determinants, maternal smoking and coffee consumption, and exclusive breastfeeding in 10205 children. Acta Paediatr 94, 1310-1319.

20. Papadimitriou G, Kotzaeridou U, Mouratidis C, Goularas P, Coe C, Ganas A \& Spencer NJ (2005) Rates and social patterning of household smoking and breastfeeding in contrasting European settings. Child Care Health Dev 31, 603-610.

21. Scott JA, Binns CW, Graham KI \& Oddy WH (2006) Temporal changes in the determinants of breastfeeding initiation. Birth 33, 37-45.

22. Bolling K (2006) Infant Feeding Survey 2005: Early Results. http://www.ic.nhs.uk/pubs/breastfeed2005 (accessed January 2009).

23. Crompton R (1998) Class and Stratification: An Introduction to Current Debates. Oxford: Polity Press.

24. Levine RF (1998) Social Class and Stratification: Classical Statements and Theoretical Debates. Lanham, MD: Rownman and Littlefield.

25. Wright EO (2005) Approaches to Class Analysis. Cambridge: Cambridge University Press.

26. Corbett J, Marryat L \& Bradshaw P (2007) Growing Up in Scotland Sweep 1 - 2005: User Guide. Edinburgh: Scottish 
Centre for Social Research; available at http://www.crfr. ac.uk/gus/Data\%20stuff/GUS\%20SW1\%20User\%20Guide.pdf

27. Anderson S, Bradshaw P, Cunningham-Burley S, Hayes F, Jamieson L, MacGregor A, Marryat L \& Wasoff F (2007) Growing Up in Scotland: A study following the lives of Scotland's children. Edinburgh: Scottish Executive Education Department; available at http://www.scotland.gov.uk/ Publications/2007/01/17162004/0

28. Rose D \& O'Reilly K (1998) The ESRC Review of Government Social Classifications: Final Report. Swindon: ESRC/ONS

29. Hawkes D, Joshi H \& Ward W (2004) Unequal Entry to Motherhood and Unequal Starts in Life: Evidence from the First Survey of the UK Millennium Cohort. London: Centre for Longitudinal Studies.

30. Hirschman C \& Butler M (1981) Trends and differentials in breast feeding: an update. Demography 18, 39-54.
31. Joshi H \& Wright RE (2004) Staring Life in Scotland in the New Millennium: Population Replacement and the Reproduction of Disadvantage. Glasgow: University of Strathclyde.

32. Arum R \& Muller W (2004) The Reemergence of Selfemployment: A Comparative Study of Self-employment Dynamics and Social Inequality. Princeton, NJ: Princeton University Press.

33. Barbieri P (2003) Social capital and self-employment: a network analysis experiment and several considerations. Int Sociol 18, 681-701.

34. Scottish Executive (2004) The Competitiveness of Higher Education in Scotland. http://www.scotland.gov.uk/ Publications/2004/03/19029/34063 (accessed January 2009).

35. Warren J (2005) The EU Blueprint - a benchmark for Scottish progress. http://www.breastfeed.scot.nhs.uk/EU_ Blueprint-Scottish_Progress_October_2005.htm (accessed October 2008). 